\title{
Relaxing decision criteria does not improve recognition memory in amnesic patients
}

\author{
PAUL J. REBER \\ University of California, San Diego, La Jolla, California \\ and \\ LARRY R. SQUIRE \\ Veterans Affairs Medical Center, San Diego, California \\ and University of Califormia, San Diego, La Jolla, California
}

\begin{abstract}
An important question about the organization of memory is whether information available in nondeclarative memory can contribute tồ performance on tasks of declarative memory. Dorfman, Kihlstrom, Cork, and Misiaszek (1995) described a circumstance in which the phenomenon of priming might benefit recognition memory performance. They reported that patients receiving electroconvulsive therapy improved their recognition performance when they were encouraged to relax their criteria for endorsing test items as familiar. It was suggested that priming improved recognition by making information available about the familiarity of test items. In three experiments, we sought unsuccessfully to reproduce this phenomenon in amnesic patients. In Experiment 3, we reproduced the methods and procedure used by Dorfman et al. but still found no evidence for improved recognition memory following the manipulation of decision criteria. Although negative findings have their own limitations, our findings suggest that the phenomenon reported by Dorfman et al. does not generalize well. Our results agree with several recent findings that suggest that priming is independent of recognition memory and does not contribute to recognition memory scores.
\end{abstract}

An important and now widely accepted idea about the organization of memory is that long-term memory is not a single mental faculty (Schacter, 1987; Squire, 1982, 1992; Tulving, 1985; Weiskrantz, 1990). The major distinction is between the capacity for conscious recollection of facts and events (declarative memory) and a collection of nonconscious (nondeclarative) learning and memory abilities that support skill and habit learning, classical conditioning, and the phenomenon of priming. Declarative memory is concerned with the deliberate retrieval of recently occurring facts and episodes, and it depends on the integrity of the medial temporal lobe and diencephalic brain systems that are damaged in amnesia. Nondeclarative memory is expressed through performance and is considered to be more automatic and less accessible to awareness than declarative memory. For example, the phenomenon of perceptual priming can occur in the absence of awareness that memory is being tested and without any deliberate effort to retrieve. Subjects

This work was supported by the Medical Research Service of the Department of Veterans Affairs, NIMH Grant MH24600 (to L.R.S.), and F32 MH11150-01Al (to P.J.R.). The authors thank James Moore and Joyce Zouzounis for research assistance. Correspondence should be addressed to L. R. Squire, Veterans Affairs Medical Center, 116A, 3350 La Jolla Village Dr., San Diego, CA 92161 (e-mail: Isquire@ucsd. edu). Paul Reber is not at the Deparrment of Psychology, Northwestern University.

- Accepted by guest associate editor Henry L. Roediger III simply identify or detect stimuli or make judgments about them.

Declarative memory is typically assessed in conventional tests of recall and recognition. One important issue is to what extent, if any, the phenomenon of priming can contribute to recognition memory performance as a result of increased perceptual fluency. Theories of recognition memory that rely on two processes (a feeling of familiarity and a recollective process) have been successful in accounting for a number of empirical findings (Gardiner, 1988; Jacoby, 1983; Mandler, 1980; Whittlesea, 1993). One possibility is that priming supports the component of recognition that depends on familiarity. Manipulations of perceptual fluency have been shown to affect the rate at which test items are endorsed as having been seen previously (Jacoby \& Whitehouse, 1989; Johnston, Dark, \& Jacoby, 1985; Johnston, Hawley, \& Elliot, 1991; Joordens \& Merikle, 1992; Whittlesea, Jacoby, \& Girard, 1990). However, these effects appear to work by influencing response bias. None of these reports has demonstrated directly that perceptual fluency can improve recognition performance (i.e., produce an increased $d^{\prime}$ discriminability score).

Memory-impaired patients provide a unique opportunity to identify the possible contribution of priming to recognition memory performance because these patients have intact perceptual and semantic priming but severely impaired declarative memory (Squire, Knowlton, \& Musen, 1993). Two approaches to this issue have been used in 
studies of memory-impaired patients. The first is based on the idea that, if priming is intact in amnesia and can also contribute to recognition memory performance, then in amnesia it should be the case that recognition memory is disproportionately spared in comparison with recall. In addition, recognition should never be so poor as to be at chance levels, so long as priming is intact. In one study of memory-impaired patients, recognition and recall were found to be proportionately impaired, in contrast to what would be expected if priming contributes to recognition (Haist, Shimamura, \& Squire, 1992). In other studies, recognition was at chance levels, despite intact priming (Hamann \& Squire, 1997; Squire, Shimamura, \& Graf, 1985).

There are two considerations that might limit the generalizability of these findings. First, with respect to the finding that recall and recognition were proportionately impaired, three studies (Hirst, Johnson, Phelps, Risse, \& Volpe, 1986; Hirst, Johnson, Phelps, \& Volpe, 1988; Shoqeirat \& Mayes, 1991) have reported recognition to be disproportionately spared in amnesia, relative to recall. In some of these studies, frontal lobe dysfunction in these patients may have contributed differentially to their impaired recall, and frontal lobe dysfunction, rather than priming, may explain why recognition is sometimes less affected than recall in memory-impaired patients (see Haist et al., 1992; Shoqeirat \& Mayes, 1991). Nevertheless, the available data comparing recall to recognition in amnesia are not consistent. Second, with respect to the finding that recognition can be at chance levels despite intact priming (Hamann \& Squire, 1997; Squire et al., 1985), such a finding does not exclude the possibility that some kind of recognition test, or some kind of test instruction, might still reveal an influence of priming on recognition performance.

Another approach that has been used to determine whether priming can influence recognition memory has been to examine directly the feeling of familiarity achieved by amnesic patients in recognition memory tasks. The question of interest is whether feelings of familiarity are preserved in amnesia and can thereby be available as a basis for making recognition judgments. Knowlton and Squire (1995) examined the "remember" and "know" responses (Tulving, 1985) made by both control subjects and amnesic patients in a recognition memory task. After endorsing each item in a recognition task, subjects were asked to judge whether they specifically remembered encountering the item previously (remember) or simply had a sense of familiarity about the item (know). The feeling of "knowing" that an item was presented on the study list without "remembering" the specific encounter with that item has been proposed to result from priming (Gardiner \& Java, 1993). If so, then amnesic patients should demonstrate relative preservation of "know" responses, while being impaired on "remember" responses. However, in the study by Knowlton and Squire, amnesic patients were equivalently impaired for both "remember" and "know" responses, indicating that both types of responses are supported by declarative memory. The more specific "remember" responses require additional declarative processing (e.g., to recover source memory), but "know" responses depend on declarative memory as well (Shimamura \& Squire, 1987; Tulving, 1989). A recent analysis of data for "remember" and "know" responses from the Knowlton and Squire study and two others (Schacter, Verfaellie, \& Anes, 1997; Schacter, Verfaellie, \& Pradere, 1996) also reached the conclusion that amnesia impairs both remembering and knowing when corrections for response bias are included (Yonelinas, Kroll, Dobbins, Lazzara, \& Knight, 1998).

A recent report suggested a specific circumstance under which priming might contribute to recognition memory performance (Dorfman, Kihlstrom, Cork, \& Misiaszek, 1995). That study examined the recognition memory performance of psychiatric patients prescribed a course of bilateral electroconvulsive therapy (ECT) to treat major affective disorder. During the course of ECT, anterograde and retrograde amnesia is a prominent side effect (Squire, 1986). In the study by Dorfman et al., patients studied a list of 28 words $10-30 \mathrm{~min}$ before the fourth, fifth, or sixth ECT treatments and then were given two recognition tests approximately $1 \mathrm{~h}$ after treatment (together with one test of cued recall and one test of word-stem completion priming). The two recognition tests differed in their instructions. For the "low-criterion" test, in order to encourage the use of familiarity in making recognition judgments, subjects were instructed to endorse a test word as one previously presented if the word seemed at all familiar. For the "high-criterion" test, subjects were told to endorse a test word only if they were relatively certain the word had appeared on the study list.

The study by Dorfman et al. (1995) followed on an earlier report (Squire et al., 1985) that priming was intact after ECT, even when recognition memory was at chance. Squire et al. used a three-alternative forced-choice recognition task to avoid response bias. Dorfman et al. used a yes/no recognition test so that response bias could be manipulated by low-criteria and high-criteria instructions. The rationale behind the low-criterion test was that it might encourage subjects to draw on whatever information about the study words was available from priming and then to use this information to improve their recognition performance. The result obtained by Dorfman et al. was that the patients performed significantly better on the low-criterion test than on the high-criterion test. Accordingly, it was suggested that the ECT patients were able to use their implicit memory to improve their recognition accuracy when they were encouraged to do so. This study is the only one known to us in which an improvement in $d^{\prime}$ discriminability was obtained in memoryimpaired patients as a result of manipulating perceptual fluency or test instructions.

In three experiments, we sought to reproduce in amnesic patients the phenomenon reported by Dorfman et al. (1995). In the first experiment, we assessed the performance of patients with medial temporal lobe or dien- 
Table 1

Characteristics of Amnesic Patients

\begin{tabular}{lcccccccc}
\hline & & & & \multicolumn{5}{c}{ WMS-R } \\
\cline { 1 - 4 } Patient & Lesion & Age (Years) & WAIS-R IQ & Attention & Verbal & Visual & General & Delay \\
\hline A.B. & HF & 58 & 104 & 87 & 62 & 72 & 54 & $<50$ \\
P.H. & HF & 74 & 120 & 117 & 67 & 83 & 70 & 57 \\
L.J. & HF & 58 & 98 & 105 & 83 & 60 & 69 & $<50$ \\
R.M. & HF & 77 & 102 & 96 & 59 & 69 & 56 & $<50$ \\
N.A. & Dien & 59 & 109 & 102 & 67 & 89 & 68 & 71 \\
R.C. & Dien & 79 & 106 & 115 & 76 & 97 & 80 & 72 \\
P.N. & Dien & 69 & 99 & 81 & 77 & 73 & 67 & 53 \\
J.W. & Dien & 59 & 98 & 104 & 65 & 70 & 57 & 57 \\
N.F. & Dien & 60 & 94 & 91 & 62 & 73 & 53 & $<50$ \\
M.H. & Unk & 75 & 107 & 104 & 83 & 83 & 78 & 80 \\
Means & & 66.8 & 103.7 & 100.2 & 70.1 & 76.9 & 65.2 & 59 \\
\hline
\end{tabular}

Note-WAIS-R, Wechsler Adult Intelligence Scale-Revised; WMS-R, Wechsler Memory Scale-Revised; HF, hippocampal formation; Dien, diencephalon; Unk, unknown. The WAIS-R and the WMS-R indices yield a mean score of 100 in the normal population, with a standard deviation of 15 . The WMS-R does not provide scores for subjects who score below 50 . Therefore, the scores below 50 were scored as 50 for calculating a group mean.

cephalic lesions using the low-criterion and high-criterion recognition procedures described by Dorfman et al. In the second experiment, we determined that amnesic patients exhibited intact priming under the conditions used in Experiment 1 . In the third experiment, we assessed lowcriterion and high-criterion recognition performance in amnesic patients and control subjects using list lengths, delays, and an experimental design that followed as closely as possible the procedure used by Dorfman et al.

\section{EXPERIMENT 1}

\section{Method}

Amnesic patients. Ten amnesic patients ( 7 men and 3 women) participated in this study. Four of the patients had alcoholic Korsakoff's syndrome. All 4 had participated in quantitative magnetic resonance imaging (MRI) studies that demonstrated reductions in the volume of the mammillary nuclei and loss of thalamic tissue density (for Patients R.C., P.N., and J.W., Squire, Amaral, \& Press, 1990; for P.N. and J.W., see also Shimamura, Jernigan, \& Squire, 1988; for N.F., unpublished observations). Patient N.F. also had bilateral reduction in the size of the hippocampal formation. Of the remaining 6 patients, 3 (P.H., L.J., and R.M.) had radiologically confirmed bilateral hippocampal damage (for P.H., Polich \& Squire, 1993; for L.J., Reed \& Squire, 1998). Patient P.H. had a history of 1- to 2-min attacks (of possible epileptic origin) in association with gastric symptoms and transient memory impairment. In 1989 , he suffered a series of small attacks that resulted in marked and persisting memory impairment. Patient L.J. became amnesic gradually in 1988-1989 without any known precipitating event. Her memory impairment has remained stable since that time. Patient R.M. became severely amnesic in 1995 following a stroke. MRI revealed reduction in the size of the hippocampal formation bilaterally, together with a left unilateral lesion involving the rostrum of the corpus callosum, the basal forebrain, and the head of the caudate nucleus. Patient A.B., who was unable to participate in MRI studies, became amnesic in 1976 after an anoxic episode and is presumed to have hippocampal damage based on his etiology. Patient N.A. became amnesic, primarily for verbal material, following a stab wound to the left diencephalic region with a miniature fencing foil (Squire, Amaral, Zola-Morgan, Kritchevsky, \&
Press, 1989; Teuber, Milner, \& Vaughn, 1968). Patient M.H. experienced a sudden onset of severe memory problems thought to be due to cerebral ischemia. The locus of her damage is unknown. All 10 patients are well characterized neuropsychologically (see Tables 1 and 2).

The patients averaged 66.8 years of age at the beginning of the study and had an average of 13.5 years of education. Immediate and delayed prose recall $(12 \mathrm{~min})$ averaged 4.7 and 0.0 segments, respectively (Gilbert, Levee, \& Catalano, 1968; maximum score = 21). Scores on other memory tests appear in Tables 1 and 2 . The mean score on the Dementia Rating Scale (DRS) was 130.9 (Mattis, 1976; maximum score $=144$ ). Most of the points lost on the DRS were from the memory subportion of the test (mean points lost $=7.2$ ). The mean score for the Boston Naming Test was $56(\mathrm{Ka}$ plan, Goodglass, \& Weintraub, 1983; maximum score $=60$ ). Scores for healthy subjects on these tests can be found elsewhere (Janowsky, Shimamura, \& Squire, 1989; Squire et al., 1990).

Control subjects. The control subjects ( 16 men and 16 women) were either employees or volunteers at the San Diego Veterans Affairs Medical Center or were recruited from the retirement community of the University of California at San Diego. The subjects were matched to the amnesic patients with respect to the mean and range of their ages, years of education, and scores on the Information and Vocabulary subtests of the Wechsler Adult Intelligence Scale-Revised (WAIS-R). They averaged 64.7 years of age (range 49-77), 14.2 years of education, and 20.8 and 51.9 on the Information and Vocabulary subtests, respectively (amnesic patients $=19.7$ and 51.3 , respectively). Immediate and delayed prose recall averaged 7.4 and 5.9 segments, respectively. The 32 subjects were assigned to one of three control groups (CON-1, $n=8 ; \mathrm{CON}-2, n=$ 12; $\mathrm{CON}-3, n=12$ ).

Materials. Four 36-item lists (A, B, C, and D) were first constructed from a pool of 144 words (average length $=5.9$ letters, range 5-7; average frequency $=44.9$ per million, range $40-51$; Kučera \& Francis, 1967). Four 72-item lists were then constructed by combining the word lists $(\mathrm{AB}, \mathrm{CD}, \mathrm{AC}$, and $\mathrm{BD})$. Lists $\mathrm{AB}$ and $C D$ were used for study. Half the subjects were given the $A B$ list, and half were given the $C D$ list. In this way, each subject studied a single list of 72 words. Lists AC and BD were then used in two separate recognition tests for each subject, as described below. For all lists, each word was printed on a separate index card for individual presentation. Each subject received a random order of the cards at both study and test. Five buffer words were also used in the study 
Table 2

Memory Test Performance

\begin{tabular}{lcccccc}
\hline \multicolumn{1}{c}{ Patient } & $\begin{array}{c}\text { Diagram } \\
\text { Recall }\end{array}$ & $\begin{array}{c}\text { Paired } \\
\text { Associate }\end{array}$ & $\begin{array}{c}\text { \% Word } \\
\text { Recall }\end{array}$ & $\begin{array}{c}\text { \% Word } \\
\text { Recognition }\end{array}$ & 50 Words & 50 Faces \\
\hline A.B. & 4 & $1,1,1$ & 33 & 83 & 32 & 33 \\
P.H. & 3 & $0,0,1$ & 27 & 84 & 36 & 34 \\
L.J. & 3 & $0,0,0$ & 40 & 93 & 33 & 29 \\
R.M. & 0 & $0,0,0$ & 16 & 72 & 26 & 30 \\
N.A. & 17 & $0,0,2$ & 49 & 93 & 34 & 42 \\
R.C. & 3 & $0,0,3$ & 19 & 85 & 37 & 30 \\
P.N. & 2 & $1,1,1$ & 29 & 83 & 31 & 31 \\
J.W. & 4 & $0,0,2$ & 28 & 96 & 29 & 34 \\
N.F. & 4 & $0,0,2$ & 36 & 76 & 28 & 27 \\
M.H. & 2 & $0,4,2$ & 41 & 91 & 27 & 36 \\
Means & 4.2 & $0.2,0.6,1.4$ & 31.8 & 85.6 & 31.3 & 32.6 \\
Control & \multicolumn{7}{c}{} & & & & & & \\
Means $(n=8)$ & 20.6 & $6.0,7.6,8.9$ & 71.0 & 97.0 & 41.1 & 38.1 \\
\hline
\end{tabular}

Note-The diagram recall score is based on delayed (12-min) reproduction of the ReyOsterrieth figure (Osterrieth, 1944; maximum score $=36$ ). Note that N.A.'s score on the diagram recall was rather good because his lesion is primarily left diencephalic and his amnesia is primarily for verbal material. The average score for the amnesic patients for copying the figure was 29.0, a normal score (Kritchevsky, Squire, \& Zouzounis, 1988). The paired associate scores are the number of word pairs recalled on 3 successive trials (maximum score $=10 /$ trial). The word recall score is the percentage of words recalled across 5 successive study-test trials. The word recognition score is the percentage of words identified correctly by yes/no recognition across 5 consecutive study-test trials. The score for words and faces is based on a $24-\mathrm{h}$ delayed recognition test of 50 words or 50 faces (modified from Warrington, 1984; maximum score $=50$, chance $=25$ ). The mean scores for control subjects shown from these tests are from Squire and Shimamura (1986).

phase (average length $=6$, average frequency per million $=35$ ) with two words presented prior to the study list and three additional words following.

Procedure. In the study session, the subjects rated how much they liked each word ( 72 words from the study list plus 5 buffer items) on a 1-5 likability scale. A card showing the scale was provided to all subjects $(1=$ dislike the word very much; $5=$ like the word very much). The patients were allowed as much time as needed to provide a response, and they typically responded within $5 \mathrm{sec}$. Rating of the study words was followed by a 5-min, conversation-filled delay for the amnesic patients (AMN) and for CON-1. CON-2 returned for the test 1 or 2 days later, and $\mathrm{CON}-3$ returned for the test 1 week after study.

Two different recognition tests were given following the delay: a low-criterion test and a high-criterion test. Test order was counterbalanced across subjects. The subjects were instructed that they would be shown words one at a time and were asked to decide whether the word had been seen in the study phase. In addition, the subjects were told that they would receive additional instructions concerning "when you should say 'yes' I have seen the word before or 'no' I have not seen the word before." For the low-criterion test, the subjects were instructed, "If you think you might have seen the word or if it seems familiar to you at all, then you should say 'yes.' If it doesn't seem familiar to you, you should say "no."' For the high-criterion tests, the subjects were instructed, "If you are relatively certain you saw the word before, then you should say 'yes.' If you're not so sure or don't think you saw the word, you should say 'no.' Say 'yes' only if you are relatively certain the word appeared before." For both tests, the subjects were additionally instructed to respond as quickly as possible. To ensure that the subjects understood the instructions and the difference between the two recognition tests, they were required to describe the instructions to the experimenter in their own words before beginning the test. The second recognition test began as soon as the first test was completed, fol- lowing a restatement of the instructions and a description of the instructions by the subject.

To help the amnesic patients remember the instructions during the course of the 72 -item recognition tests, the instructions were written on cards and placed in view of all subjects. In addition, the experimenter reviewed the instructions four times for all subjects after presentation of the 6th, 23rd, 41 st, and 58th test words.

\section{Results}

Hit rates and false-alarm rates for the four groups for both the low-criterion and high-criterion recognition tests are shown in Figure 1. If the subjects followed the test instructions, the endorsement rate of test items (the average of the hit rate and the false-alarm rate) should be higher in the low-criterion test than in the high-criterion test. To determine the effect of instructions, a $4 \times 2$ analysis of variance (ANOVA; 4 subject groups $\times 2$ test conditions) was applied to the percent of test items endorsed (average of hit rate and false-alarm rate). There was no effect of group $[F(3,38)=1.10]$, a strong effect of test condition $[F(1,38)=25.9, p<.001]$, and no interaction $[F(3,38)=$ $0.52]$. The effect of test condition reflects the higher overall endorsement rate in the low-criterion test than in the high-criterion test. Additionally, separate one-way ANOVAs revealed significantly higher endorsement rates in the low-criterion condition for each control group [for CON-1, $F(1,7)=18.2$; for CON-2, $F(1,11)=8.40$; for CON-3, $F(1,11)=8.34$; all $p s<.02]$. The increase in endorsement rate in the low-criterion condition for amnesic patients was marginally significant $[F(1,9)=4.40$, 


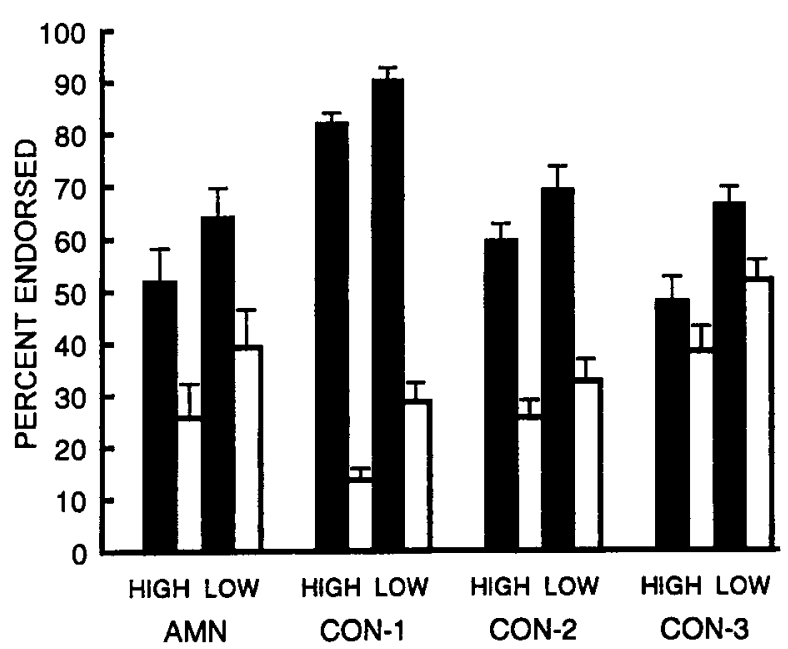

Figure 1. Percent hits (shaded bars) and percent false alarms (open bars) in Experiment 1 for the high-criterion (HIGH) and low-criterion (LOW) tests for the amnesic patients (AMN) and three control groups tested after study-test delays of 5 min (CON-1), 1 or 2 days (CON-2), or 1 week (CON-3). Bars indicate the standard errors of the mean.

$p<.07$ ] (and similar in magnitude to the increase observed in the control groups). These results indicate that, overall and in accordance with the instructions, the subjects endorsed significantly more items in the low-criterion test than in the high-criterion test.

Recognition performance ( $d^{\prime}$ discriminability scores) for the low-criterion and high-criterion tests is shown in Figure 2 for the amnesic patients (AMN) and for the three control groups tested at different study-test delays (CON-1, CON-2, and CON-3). All four groups exhibited significant recognition memory of the studied material in both the low-criterion and high-criterion tests ( $d^{\prime}$ was reliably greater than zero in all cases; $t \mathrm{~s}>2.32$, $p \mathrm{~s}<.05)$. The important finding was that all four groups obtained virtually the same $d^{\prime}$ score for the low-criterion test and the high-criterion test. A $4 \times 2$ ANOVA across the four groups (between-subjects) and the low-criterion and high-criterion tests (within-subjects) indicated a strong effect of group $[F(3,38)=35.5, p<.001]$, reflecting the superior performance of the CON-1 (5-min study-test delay) group in comparison with the other groups (AMN, CON-2, CON-3). There was no effect of test condition $[F(1,38)=0.018]$ and no group $\times$ test condition interaction $[F(3,38)=0.79]$. In addition, none of the groups individually exhibited a trend for better recognition performance on the low-criterion test than on the high-criterion test (separate one-way ANOVAs for each group based on $\left.d^{\prime}, F \mathrm{~s}<1.14\right)$.

The same results were obtained when the data were analyzed using a percent correct measure of recognition performance (hits plus correct rejections divided by 72). A $4 \times 2$ ANOVA involving the four groups and the two tests revealed a strong effect of group $[F(3,38)=39.9, p<$ $.001]$, no effect of test condition, and no group $\times$ test inter- action $(F \mathrm{~s}<1.0)$. Individual one-way ANOVAs for each group confirmed that performance was similar on the low-criterion and high-criterion tests $(F \mathrm{~s}<1.25)$.

Finally, the data were analyzed to determine whether there was an effect of test order using a $4 \times 2 \times 2$ ANOVA (4 groups $\times 2$ test types $\times 2$ possible test orders). This analysis revealed the expected effect of group $[F(3,34)=$ $39.7, p<.001]$, but no effect of test order $[F(1,34)=$ $2.27, p>.14]$, no effect of test type $[F(1,24)=0.20]$, and no interactions of test order with group and/or test type $(F \mathrm{~s}<2.12, p \mathrm{~s}>.10)$.

\section{Discussion}

The amnesic patients exhibited impaired recognition memory performance when compared with control subjects tested at the same 5-min delay ( $\mathrm{CON}-1)$. Control subjects tested at longer delays (1-2 days and 1 week) performed similarly to the amnesic patients and were also impaired relative to the control subjects tested at a 5-min delay. All four subject groups endorsed more items in the low-criterion test than in the high-criterion test, in accordance with the test instructions. Nevertheless, the test instructions had no measurable effect on recognition memory accuracy. Amnesic patients performed similarly on the low-criterion and high-criterion recognition tests. Similarly, none of the three control groups showed any tendency to improve their recognition performance on the low-criterion test. That is, for all groups, including the amnesic patients, both the hit rate and the false-alarm rate increased in the low-criterion condition, but there was no change in $d^{\prime}$.

\section{EXPERIMENT 2}

In Experiment 1, manipulating decision criteria with the test instructions did not influence recognition memory judgments. One possible concern is that priming was not assessed independently in this experiment. If priming were weak or absent in the particular conditions used in Experiment 1, then priming could not have benefited recognition memory. Accordingly, in Experiment 2, 16-17 months after Experiment 1, we assessed priming using most of the same words that had been presented in Experiment 1 . We also used the same-sized study list (72 words) and the same study-test delay ( $5 \mathrm{~min})$.

\section{Method}

Amnesic patients. With the exception of Patient R.M., all the amnesic patients from Experiment 1 participated in this experiment.

Control subjects. The control subjects ( 5 men and 5 women) were recruited as in Experiment 1. They averaged 65.0 years of age (range 49-75), 13.3 years of education, and 20.5 and 52.9 on the Information and Vocabulary subtests of the WAIS-R, respectively (amnesic patients $=19.7$ and 51.3, respectively). Immediate and delayed prose recall averaged 7.4 and 5.6 segments, respectively. Five of the control subjects had also participated in Group CON-1 in Experiment 1 .

Materials. A set of 144 words was assembled such that no 2 had the same three-letter stem (average length $=5.9$ letters, range 5-7; average frequency $=45.5$ per million, range $40-51$; Kučera \& Fran- 


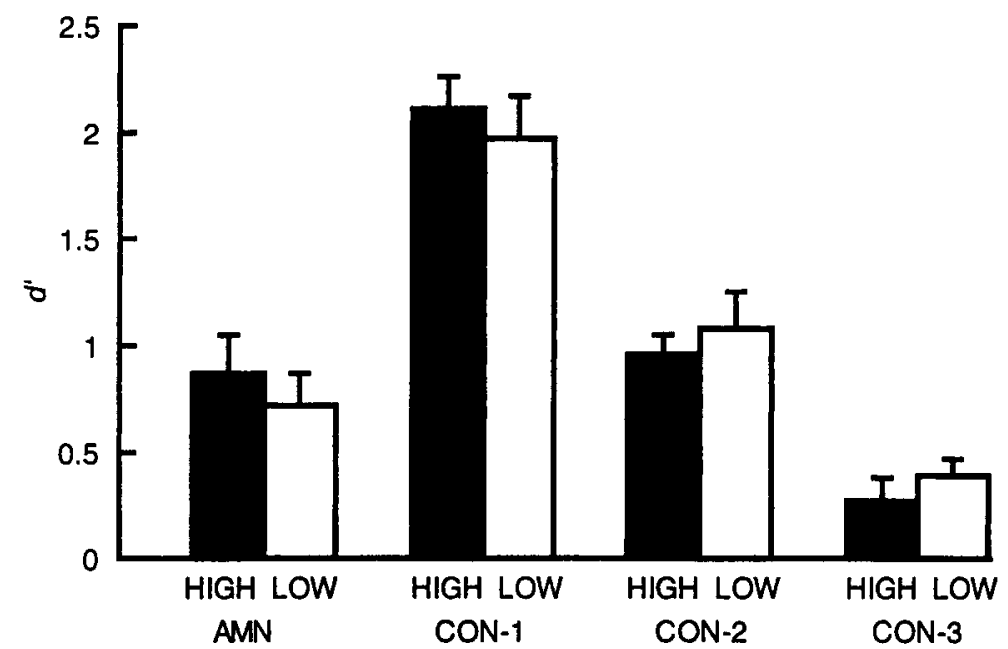

Figure 2. Recognition performance in Experiment 1 expressed as $d^{\prime} . \mathbf{A M N}=$ amnesic patients; $\mathrm{CON}-1, \mathrm{CON}-2$, and $\mathrm{CON}-3$ = control subjects tested after delays of 5 min, 1 or 2 days, or 1 week, respectively. Bars indicate the standard errors of the mean.

cis, 1967). One hundred thirty of the words came from the lists used in Experiment 1. The words were assigned to six lists of 24 words each (balanced for baseline completion rate).

Procedure. Each subject received a unique combination of three 24-item lists at study ( 72 words total). As in Experiment 1, the subjects rated how much they liked each word on a 1-5 likability scale. A card showing the scale was provided to all subjects $(1=$ dislike the word very much; 5 = like the word very much). The patients were allowed as much time as needed to provide a response, and they typically responded within $5 \mathrm{sec}$. Rating of the study words was followed by a 5 -min, conversation-filled delay and then by the priming test. For the priming test, 144 three-letter word stems were presented one at a time, and the subjects were asked to complete each stem to form "the first word that comes to mind."

\section{Results and Discussion}

Percent word-stem completion for study words, percent baseline word-stem completion, and percent priming are shown in Figure 3. The amnesic patients and control subjects performed similarly $[t \mathrm{~s}(17)<0.8$, for each of the three comparisons]. Percent priming scores (study words completed minus baseline words completed) were $12.5 \%$ for the amnesic patients and $16.7 \%$ for the control subjects. Both scores were well above zero $(t \mathrm{~s}>2.7, p<$ .05 ). These data indicate that priming did occur under the conditions of Experiment 1. Yet, despite the fact that priming occurred, we were unable to improve recognition memory performance in Experiment 1 using a test procedure that had been designed to allow recognition to benefit from priming effects.

Five of the control subjects in Experiment 2 had also participated in Experiment 1 and had therefore already seen most of the study words that were used in Experiment 2. To assess whether this earlier exposure to study words affected their level of priming, the priming score obtained by the 5 subjects who had participated in Experiment 1 was compared with the priming score obtained by the remaining 5 subjects. The subjects who had pre- viously participated in Experiment 1 exhibited a higher priming score than the other subjects $(20.3 \%$ vs. $13.1 \%)$, but the effect was not significant $[t(8)=1.37, p>.20]$. Given that Experiment 2 was administered 16-17 months after Experiment 1, it seems unlikely that this difference reflects a real difference in priming performance.

\section{EXPERIMENT 3}

There were several differences between the conditions of our Experiment 1 and the procedures followed by Dorfman et al. (1995). Notable among these was that our study list was longer ( 72 words vs. 28 words) and our two recognition tests each contained more words from the study lists ( 36 words vs. 7 words). In addition, our test session consisted of only two recognition tests, whereas Dorfman et al. gave the high-criterion test following a stem cued-recall test and the low-criterion test following a word-stem completion test. In view of these differences, we carried out Experiment 3 with the objective of reproducing as closely as possible the method and procedures of the original study by Dorfman et al.

\section{Method}

Amnesic patients. Eight of the 10 amnesic patients from Experiment 1 participated in this study (all but Patients M.H. and R.W.).

Control subjects. The control subjects ( 3 men and 5 women) were recruited as in Experiment 1. They averaged 64.6 years of age (range 52-74), 15.4 years of education, and 21.1 and 53.8, respectively, on the Information and Vocabulary subtests of the WAIS-R. Immediate and delayed prose recall averaged 8.1 and 6.8 segments, respectively.

Materials. Two sets of 28 words used previously in word-stem priming experiments (Hamann \& Squire, 1996) were assembled (average length $=6.3$ letters, range $4-8$; average frequency $=52.1$ per million; Kučera \& Francis, 1967). The first set of 28 words was used for the stem-completion and stem cued-recall tests. The second set of 28 words was used for the low- and high-criterion recog- 


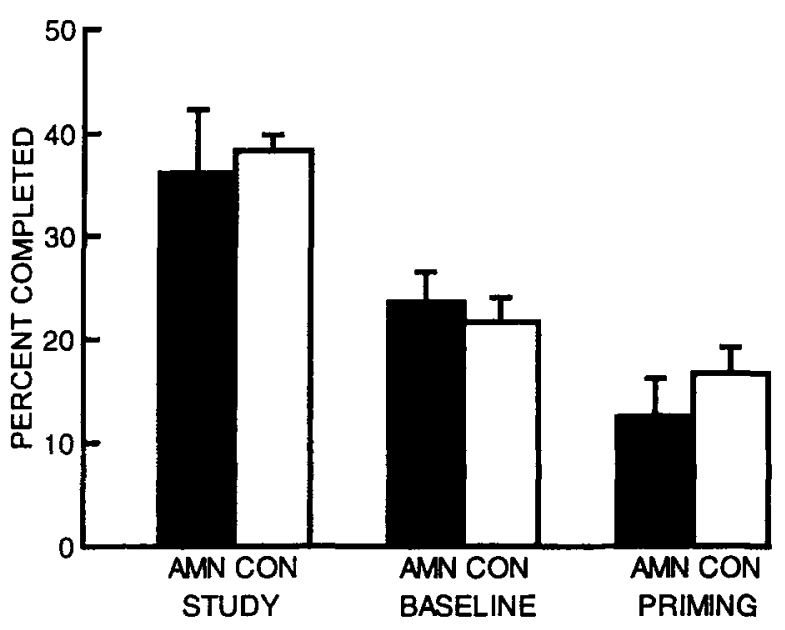

Figure 3. Percent word-stem completion for study words and baseline words in Experiment 2. Priming = study words minus baseline words; shaded bars $=$ amnesic patients (AMN, $n=9$ ); open bars $=$ control group $(\mathrm{CON}, n=10)$. Bars indicate the standard errors of the mean.

nition tests. Each set of 28 words was further divided into two lists of 14 words, matched according to frequency of occurrence. For the first set of 28 words, the two 14-word lists served as items for the stem completion test and the stem cued-recall test. These materials were balanced across subjects, so that items served equally often as items for stem completion and as items for cued recall. For the second set of 28 words, the two 14-word lists provided items for the low- and high-criterion recognition tests. These materials were also balanced across subjects in the same way as the other two 14-word lists. Finally, each list of 14 items was divided into groups of 7 items. Half of these items were available as items for the study list; the other half were available to measure baseline performance in the case of the stem completion test, as fillers in the word-stem cued recall test and as distractor items in the two recognition tests. These materials were balanced across subjects so that item's were equally likely to appear on the study list or as nonstudied items on one of the four tests.

Procedure. Each subject received 28 study words to rate on a $1-5$ likability scale. The 28 study words were preceded and followed by 3 buffer words. One hour later, four memory tests were given: a word-stem priming test, a test of word-stem cued recall, and two recognition memory tests that used the same procedure as in Experiment 1. In the word-stem completion test, the subjects were shown 14 three-letter word stems and asked to produce "the first word that comes to mind" (as in Experiment 2). Seven of the word stems could be completed to form study words. For the stem cued-recall test, the subjects were shown 14 three-letter word stems and asked to complete the stem with a word from the study list. Seven of these word stems were the stems of study words. Both of the stem test lists were preceded by 2 practice stems. For each of the two recognition tests, 14 words were presented, 7 of which had appeared on the study list. Each subject was given one of two test orders: word-stem completion, low-criterion recognition test, stem cued recall, and high-criterion recognition test; or stem cued recall, high-criterion recognition test, word-stem completion, and lowcriterion recognition test (as in Dorfman et al., 1995).

\section{Results}

The results for all four tests are shown in Figure 4. The amnesic patients exhibited marginally impaired cued- recall performance (Figure 4A), recalling $16.9 \%$ of the study words compared with $29.4 \%$ for the control subjects $[t(14)=1.87, p<.09]$. Word-stem completion priming (Figure 4B) was also lower for the amnesic patients than for the control subjects, though the difference did not reach significance. Baseline stem completion was similar for the two groups $(\mathrm{AMN}=13.4 \%, \mathrm{CON}=12.5 \%)$, but the control subjects exhibited more priming than the amnesic patients $[17.9 \%$ vs. $4.5 \% ; t(14)=1.68, p>.10]$ and the level of priming exhibited by the amnesic patients was not greater than chance $[t(7)=0.83]$. Two considerations suggest that the control subjects likely obtained their superior score by drawing on declarative memory. First, a relatively short list of words (28) was encoded with a semantic orienting task, conditions under which normal subjects readily use declarative memory strategies to perform word-stem completion tasks (Hamann \& Squire, 1996). Second, with retention intervals as long as $2 \mathrm{~h}$, studies of word-stem completion in memory-impaired patients have found quite low levels of priming even when a semantic encoding task is used $(2.9 \%$ priming score, Graf, Squire, \& Mandler, 1984; $9 \%$ priming score, Squire, Shimamura, \& Graf, 1987).

Hit rates and false-alarm rates for the two recognition tests are shown in Figure 4C. Across the two tests, the control subjects exhibited better recognition performance than did the amnesic patients [hits plus correct rejections, $\mathrm{CON}=83.3 \%$ correct, $\mathrm{AMN}=59.8 \%$ correct; $t(14)=$ $4.5, p<.001]$. The amnesic patients endorsed more of the test items in the low-criterion test than in the high-criterion test [ $54.9 \%$ vs. $43.3 \% ; t(7)=2.32, p<.06]$, indicating that they followed the test instructions. In contrast, the control subjects did not endorse more items in the lowcriterion condition than in the high-criterion condition $[48.2 \%$ vs, $47.8 \% ; t(7)=0.11, p>.10]$. The lack of an effect of test instructions on the endorsement rate of control subjects was also observed by Dorfman et al. (1995) and was presumably due to the relatively easy recognition test that was used. Only 14 test items were presented (7 study words and 7 distractor words). Control subjects recognized approximately 5 of the 7 study words and incorrectly endorsed approximately 1 of the 7 distractor words. As suggested by Dorfman et al., when performance is as close to ceiling levels as this, it is difficult to influence endorsement rate by manipulating test instructions.

Recognition performance ( $d^{\prime}$ discriminability scores) for the two recognition tests is shown in Figure 4D. Although the amnesic patients endorsed more items in the low-criterion test, $d^{\prime}$ scores for the two tests were virtually identical. The control subjects also exhibited similar performance for the two recognition tests. A $2 \times 2$ ANOVA ( 2 groups $\times 2$ recognition tests) indicated a strong effect of group $[F(1,14)=19.7, p<.001]$, reflecting the superior performance of the control group in comparison to the amnesic patients. There was no effect of test condition $[F(1,14)=1.8, p>.10]$ and no interaction $[F(1,14)=$ $0.3]$. Thus, there was no evidence for an improvement in recognition memory performance in the low-criterion 

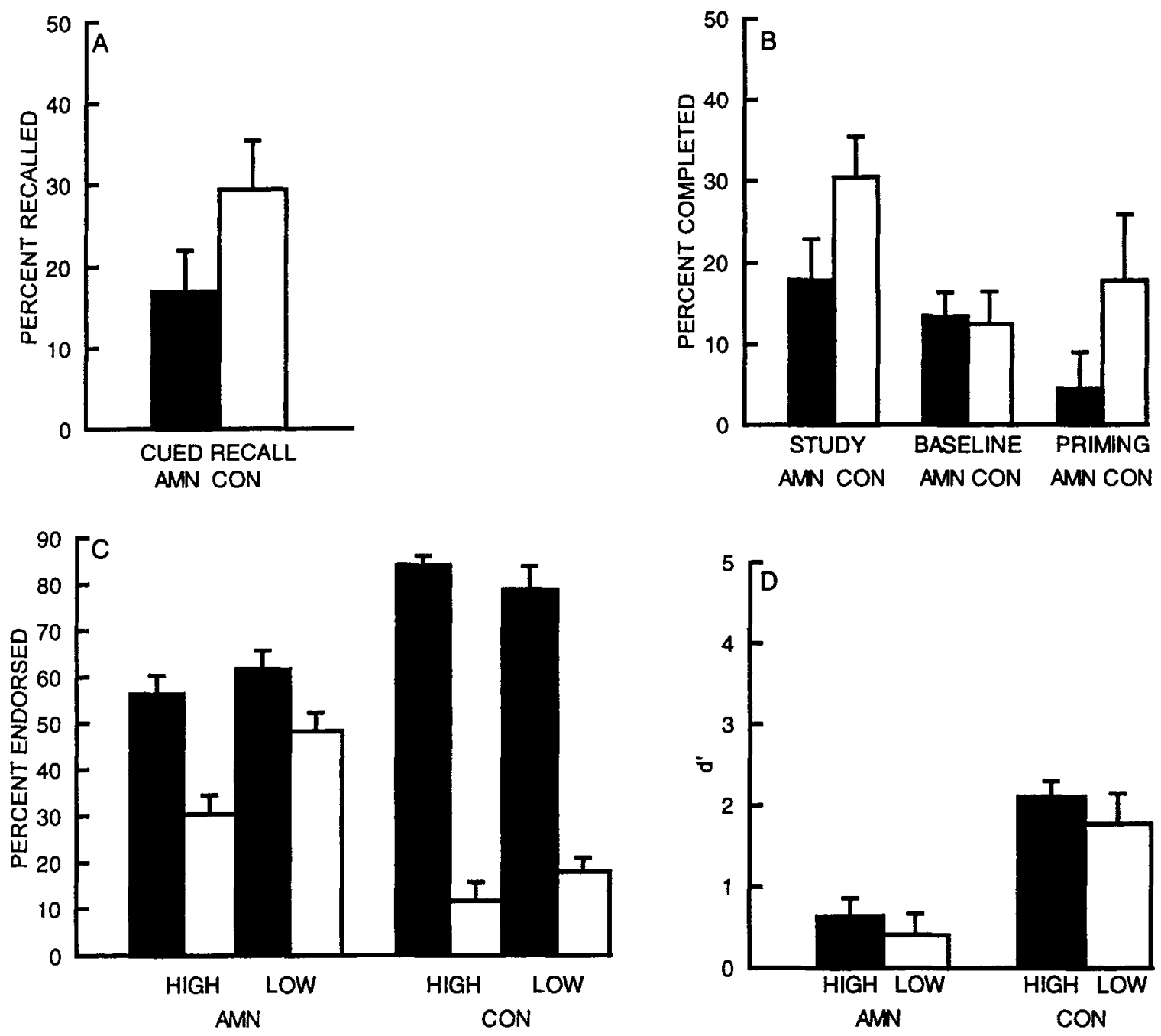

Figure 4. (A) Cued recall performance for amnesic patients (AMN, shaded bar, $n=8$ ) and controls (CON, open bar, $n=$ 8). (B) Percent word-stem completion for study words and baseline words. Priming = study words minus baseline words; shaded bars $=$ amnesic patients $(\mathrm{AMN}, \boldsymbol{n}=8)$; open bars $=$ controls $(\mathrm{CON}, \boldsymbol{n}=8)$. (C) Percent hits (shaded bars) and percent false alarms (open bars) for the high-criterion (HIGH) and low-criterion (LOW) recognition memory tests. AMN = amnesic patients $(n=8)$; CON $=$ controls $(n=8)$. (D) Recognition memory performance measured by $d^{\prime}$ for the highcriterion (shaded bars) and low-criterion (open bars) tests. AMN = amnesic patients $(n=8)$; CON $=$ controls $(n=8)$. Bars indicate the standard errors of the mean.

condition as the result of manipulating test instructions. The same results were obtained when the data were analyzed using a percent correct measure of recognition performance (hits plus correct rejections). Indeed, performance was slightly better in the high-criterion condition than in the low-criterion condition (AMN $=56.7 \%$ and $62.9 \%$ for the low-criterion and high-criterion conditions, respectively; $\mathrm{CON}=80.4 \%$ and $86.2 \%$ ). It cannot be argued that the amnesic patients failed to improve their performance in the low-criterion condition because of floor effects in the high-criterion condition. The amnesic patients performed above chance levels on the highcriterion test whether performance was measured by $d^{\prime}$ [mean $d^{\prime}=0.63 ; t(7)=2.9, p<.05$ ] or by percent correct [hits plus correct rejections $=62.9 \%$ correct; $t(7)=3.7$, $p<.01]$.

\section{GENERAL DISCUSSION}

As expected, the patients consistently performed more poorly than the control subjects on the recognition tests. In addition, all the subject groups (except for control subjects in Experiment 3) endorsed more items (both targets and distractors) in the low-criterion test than in the high-criterion test, in accordance with the test instructions. Yet there was no hint of improved performance in the low-criterion condition by any group. In Experiments 1 and 3, amnesic patients performed similarly on the low- 
criterion and high-criterion recognition tests. Similarly, the three control groups in Experiment 1 and the control group in Experiment 3 also performed similarly on the low-criterion and high-criterion tests. Thus, encouraging the subjects to use familiarity in making their recognition judgments did not improve recognition performance.

Dorfman et al. (1995) reported that instructions encouraging ECT patients to use familiarity led to improved recognition memory performance. Specifically, in that report, hit rate increased without a concomitant increase in false-alarm rate. We did not find this effect for the 10 amnesic patients studied here. Indeed, the largest increase in $d^{\prime}$ for an individual patient in the low-criterion test of Experiment 1 was +0.82 (the change in $d^{\prime}$ for the other amnesic patients ranged from -0.64 to +0.20 ), and the largest increase in Experiment 3 was +0.65 (range for other patients $=-1.56$ to +0.37 ). Dorfman et al. observed an average increase in $d^{\prime}$ of +1.29 in the low-criterion test compared with the high-criterion test.

Dorfman et al. (1995) found, as we did in Experiment 3 , that the recognition scores of control subjects did not improve significantly in the low-criterion condition (nor did their endorsement rate significantly increase). This result was likely due to the fact that the control subjects performed at or near ceiling on both recognition tests, presumably because of the short study list that was used, and the low-criterion test could not improve performance further, relative to the high-criterion test. Note, however, that, in Experiment 1, our control subjects were not at ceiling, even at the shortest (5-min) delay. If the instructional manipulation had enabled priming to contribute more effectively to recognition memory, the performance of these control subjects could have improved. Yet each of the three control groups exhibited a significant increase in endorsement rate in the low-criterion condition without improving either the percent correct score or the $d^{\prime}$ score.

Two features of the amnesia associated with ECT may be relevant to understanding the differences between our two studies. First, ECT patients, particularly the elderly, are often confused during the first hour after bilateral treatment. The patients tested by Dorfman et al. (1995) averaged 62.1 years of age. If these patients experienced some confusion during the recognition test, which was administered 50-60 min after treatment, their confusion may have interfered with their ability to make recognition judgments. If so, instructions to set a relaxed threshold for endorsing items (the low-criterion condition) might actually encourage subjects to use their memory more consistently and successfully than they were able to do in the high-criterion condition.

A second and related point is that ECT patients are unaccustomed to their memory dysfunction and, as a result, may be unable to rely on weak, residual declarative memory to endorse a test item as having been seen recently. Such a difficulty would be expected to affect memory performance more strongly in the high-criterion condition than in the low-criterion condition. Amnesic patients, who are accustomed to their condition, could have learned that weak memory traces can actually index recent events. In that case, stable amnesic patients may be able to use their residual memory equally well in both the low-criterion and the high-criterion condition. These considerations raise the possibility that the results reported by Dorfman et al. (1995) were due to a meta-memory impairment following ECT that was sensitive to test instructions (relaxing the response criterion in the low-criterion condition). One could suppose that amnesic patients have learned to rely on a priming contribution to recognition memory and that an instructional manipulation could not further increase this contribution. However, this idea cannot account for the finding of consistently chance levels of recognition memory performance in a severely impaired amnesic patient who nevertheless exhibits normal priming (Hamann \& Squire, 1997).

The level of priming observed in our Experiment 3 and that reported by Dorfman et al. (1995) deserve mention. The patients prescribed ECT obtained a word-stem completion priming score of $26 \%$ following a study-test interval of $60-90 \mathrm{~min}$. In our attempt to replicate their procedure directly (Experiment 3 ), we observed only $4.5 \%$ word-stem completion priming at a 60-min delay. As mentioned in the Results section of Experiment 3, wordstem completion priming is often weak after $1 \mathrm{~h}$ or more. In a comprehensive study by Roediger, Weldon, Stadler, and Riegler (1992), college students obtained priming scores of $10 \%-15 \%$ after a study-test delay of $90-$ $120 \mathrm{~min}$ (Experiments 2 and 3 ). Other studies have found word-stem completion priming scores after delays of $90 \mathrm{~min}$ to $24 \mathrm{~h}$ of $3.3 \%$ to $7.3 \%$ (Chen \& Squire, 1990 ), $8.8 \%$ (Graf \& Mandler, 1984), 13\% (Craik, Moscovitch, $\&$ McDowd, 1994, estimated from Figures 2 and 3), and 13.5\%-17\% (McBride \& Dosher, 1997). Higher levels of word-stem completion priming are often associated with a contribution of declarative memory (e.g., Hamann \& Squire, 1996). It is true that the low cued-recall score of the ECT patients ( $5 \%$ correct) studied by Dorfman et al. is not indicative of much residual declarative memory. However, the patients were discouraged from guessing, so it is difficult to know how much declarative memory was available. In any case, even if residual declarative memory did contribute to the priming scores of the ECT patients, it is still unclear why Dorfman et al. obtained an effect of test instructions on recognition performance and we did not.

In summary, we were unable to obtain the finding reported by Dorfman et al. (1995) that instructional manipulations allow priming to improve recognition memory performance. Although Experiment 1 used a different procedure than the Dorfman et al. experiment, the failure to find an effect (in a case where priming was robust) suggests that the effect of instructional manipulation might be specific to the exact procedure and test items (or patient population) used by Dorfman et al. The failure in Experiment 3 to observe robust priming (and the failure 
as well to observe an effect of the instructional manipulation) raises the general question of whether priming is sufficiently robust and persistent to support familiarity. One possibility is that the instructional manipulation effect could be specific to the word stimuli used by Dorfman et al., since we followed closely their experimental procedure (but did not use their words). Although negative results have their own limitations, our findings suggest that the phenomenon reported by Dorfman et al. does not generalize well. Our results are consistent with a number of recent findings (Gabrieli, Fleischman, Keane, Reminger, \& Morrell, 1995; Haist et al., 1992; Hamann \& Squire, 1997; Knowlton \& Squire, 1995; Wagner, Gabrieli, \& Verfaellie, 1997) that suggest that nondeclarative memory (priming) is independent of recognition memory and does not contribute to recognition memory scores.

\section{REFERENCES}

ChEN, K. S., \& SQuiRe, L. R. (1990). Strength and duration of wordcompletion priming as a function of word repetition and spacing. Bulletin of the Psychonomic Society, 28, 97-100.

Craik, F. I. M., Moscovitch, M., \& McDowd, J. M. (1994). Contributions of surface and conceptual information to performance on implicit and explicit memory tasks. Journal of Experimental Psychology: Learning, Memory, \& Cognition, 20, 864-875.

Dorfman, J., Kinlstrom, J. F., Cork, R. C., \& Misiaszek, J. (1995) Priming and recognition in ECT-induced amnesia. Psychonomic Bulletin \& Review, 2, 244-248.

Gabrieli, J. D. E., Fleischman, D. A., Keane, M. M., Reminger, S. L., \& Morrell, F. (1995). Double dissociation between memory systems underlying explicit and implicit memory in the human brain. Psychological Science, 6, 76-82.

GARDINER, J. M. (1988). Recognition failures and free-recall failures Implications for the relation between recall and recognition. Memory \& Cognition, 16, 446-451.

GARDINER, J. M., \& JAVA, R. I. (1993). Recognizing and remembering In A. Collins, S. Gathercole, M. Conway, \& P. Morris (Eds.), Theories of memory (pp. 163-188). Hillsdale, $\mathrm{NJ}$ : Erlbaum.

Gilbert, J., Levee, R., \& Catalano, K. (1968). A preliminary report on a new memory scale. Perceptual \& Motor Skills, 27, 277-278.

GRAF, P., \& MANDLER, G. (1984). Activation makes words more accessible, but not necessarily more retrievable. Journal of Verbal Learning \& Verbal Behavior, 23, 553-568.

Graf, P., SQuire, L. R., \& MANDLER, G. (1984). The information that amnesic patients do not forget. Journal of Experimental Psychology: Learning, Memory, \& Cognition, 10, 164-178.

Haist, F., Shimamura, A. P., \& Squire, L. R. (1992). On the relationship between recall and recognition memory. Journal of Experimental Psychology: Learning, Memory \& Cognition, 18, 691-702.

HaMANN, S. B., \& SQUiRE, L. R. (1996). Level-of-processing effects in word-completion priming: A neuropsychological study. Journal of Experimental Psychology: Learning, Memory, \& Cognition, 22, 933-947.

HAMANN, S. [B.], \& SQUIRE, L. R. (1997). Intact perceptual memory in the absence of conscious memory. Behavioral Neuroscience, 111, 850-854.

Hirst, W., Johnson, M. K., Phelps, E. A., Risse, G., \& Volpe, B. T. (1986). Recognition and recall in amnesics. Journal of Experimental Psychology: Learning, Memory, \& Cognition, 12, 445-451.

Hirst, W., Johnson, M. K., Phelps, E. A., \& Volpe, B. T. (1988). More on recognition and recall in amnesics. Journal of Experimental Psychology: Learning, Memory, \& Cognition, 14, 758-762.

JACOBY, L. L. (1983). Perceptual enhancement: Persistent effects of an experience. Journal of Experimental Psychology: Learning. Memory, \& Cognition, 9, 21-38.

JACOBY, L. L., \& WhiteHOUSE, K. (1989). An illusion of memory: False recognition influenced by unconscious perception. Journal of Experimental Psychology: General, 118, 126-135.
Janowsky, J. S., Shimamura, A. P., \& SQuire, L. R. (1989). Source memory impairment in patients with frontal lobe lesions. Neuropsychologia, 27, 1043-1056.

Johnston, W. A., Dark, W. J., \& JACOBy, L. L. (1985). Perceptual fluency and recognition judgments. Journal of Experimental Psychology: Learning, Memory, \& Cognition, 11, 3-11.

Johnston, W. A., HaWley, K. J., \& Elliot, M. G. (1991). Contribution of perceptual fluency to recognition judgments. Journal of Experimental Psychology: Learning, Memory, \& Cognition, 17, 210 223.

JOORDENS, S., \& MERIKLE, P. M. (1992). False recognition and perception without awareness. Memory \& Cognition, 20, 151-159.

Kaplan, E. F., Goodglass, H., \& Weintraub, S. (1983). The Boston naming test. Philadelphia: Lea Febiger.

KNOWLTON, B. J., \& SQUIRE, L. R. (1995). Remembering and knowing: Two different expressions of declarative memory. Journal of Experimental Psychology: Learning, Memory, \& Cognition, 21, 699-710.

KRITCHEVSKY, M., SQUIRE, L. R., \& ZouZounis, J. A. (1988). Transient global amnesia: Characterization of anterograde and retrograde amnesia. Neurology, 38, 213-219.

KUČERA, H., \& FRANCIS, W. (1967). Computational analysis of presentday American English. Providence, RI: Brown University Press.

MANDLER, G. (1980). Recognizing: The judgment of previous occurrence. Psychological Review, 87, 252-271.

MATTIS, S. (1976). Dementia rating scale. In R. Bellack \& B. Keraso (Eds.), Geriatric psychiatry (pp. 77-121). New York: Grune \& Stratton.

MCBRIDE, D. M., \& DosheR, B. A. (1997). A comparison of forgetting in an implicit and explicit memory task. Journal of Experimental Psychology: General, 126, 371-392.

OSTERRIETH, P. A. (1944). Le test de copie d'une figure complexe [The test of copying a complex figure]. Archives de Psychologie, 30, 206356.

Polich, J., \& SQUiRe, L. R. (1993). P300 from amnesic patients with bilateral hippocampal lesions. EEG Clinical Neuropsychology, 86, 408-417.

REED, J., \& SQuire, L. R. (1998). Retrograde amnesia for facts and events: Findings from four new cases. Journal of Neuroscience, 18, 3943-3954.

Roediger, H. L., III, Weldon, M. S., Stadler, M. L., \& Riegler, G. L. (1992). Direct comparison of two implicit memory tests: Word fragment and word stem completion. Journal of Experimental Psychology: Learning, Memory, \& Cognition, 18, 1251-1269.

SCHACTER, D. L. (1987). Implicit memory: History and current status. Journal of Experimental Psychology: Learning, Memory, \& Cognition, 13, 501-518.

SChacter, D. L., Verfaellie, M., \& ANEs, M. D. (1997). Illusory memories in amnesic patients: Conceptual and perceptual false recognition. Neuropsychology, 11, 331-342.

Schacter, D. L., Verfaellie, M., \& Pradere, D. (1996). Neuropsychology of memory illusions: False recall and recognition in amnesic patients. Journal of Memory \& Language, 35, 319-334.

Shimamura, A. P., JeRnigan, T. L., \& SQUiRe, L. R. (1988). Korsakoff's syndrome: Radiological (CT) findings and neuropsychological correlates. Journal of Neuroscience, 8, 4400-4410.

Shimamura, A. P., \& SQuire, L. R. (1987). A neuropsychological study of fact memory and source amnesia. Journal of Experimental Psychology: Learning, Memory, \& Cognition, 13, 464-473.

ShoqeIRAT, M. A., \& MAYES, A. R. (1991). Disproportionate incidental spatial memory and recall deficits in amnesia. Neuropsychologia, 29, 749-769.

SQUIRE, L. R. (1982). The neuropsychology of human memory. Annual Review of Neuroscience, 5, 241-273.

SQuIRE, L. R. (1986). Memory functions as affected by electroconvulsive therapy. In S. Malitz \& H. A. Sackheim (Eds.), Electroconvulsive therapy: Clinical and basic issues (Annals of the New York Academy of Sciences, Vol. 462, pp. 307-314). New York: New York Academy of Sciences.

SQUiRE, L. R. (1992). Memory and the hippocampus: A synthesis from findings with rats, monkeys, and humans. Psychological Review, 99 , 195-231. 
Squire, L. R., Amaral, D. G., \& Press, G. A. (1990). Magnetic resonance measurements of hippocampal formation and mammillary nuclei distinguish medial temporal lobe and diencephalic amnesia. Journal of Neuroscience, 10, 3106-3117.

Squire, L. R., Amaral, D. G., Zola-Morgan, S., Kritchevsky, M., \& PRESS, G. A. (1989). Description of brain injury in the amnesic patient N.A. based on magnetic resonance imaging. Experimental Neurology, 105, 23-25.

SQuire, L. R., KNOWlton, B., \& Musen, G. (1993). The structure and organization of memory. Annual Review of Psychology, 44, 453-495.

Squire, L. R., \& ShimamuRa, A. P. (1986). Characterizing amnesic patients for neurobehavioral study. Behavioral Neuroscience, 100, 866877.

Squire, L. R., Shimamura, A. P., \& Graf, P. (1985). Independence of recognition memory and priming effects: A neuropsychological analysis. Journal of Experimental Psychology: Learning, Memory, \& Cognition, 11, 37-44.

Squire, L. R., Shimamura, A. P., \& Graf, P. (1987). Strength and duration of priming effects in normal subjects and amnesic patients. Neuropsychologia, 25, 195-210.

Teuber, H. L., Milner, B., \& Vaughn, H. G. (1968). Persistent anterograde amnesia after stab wound of the basal brain. Neuropsychologia, 6, 267-282.

Tulving, E. (1985). Memory and consciousness. Canadian Psychologist, 26, 1-12.
TulviNG, E. (1989). Remembering and knowing the past. American Scientist, 77, 361-367.

WaGner, A. D., Gabrieli, J. D. E., \& Verfaellie, M. (1997). Dissociations between familiarity processes in explicit recognition and implicit perceptual memory. Journal of Experimental Psychology: Learning, Memory, \& Cognition, 23, 305-323.

WARRINGTON, E. K. (1984), Recognition memory test. Windsor: FERNelson.

Weiskrantz, L. (1990). Problems of learning and memory: One or multiple memory systems? Philosophical Transactions of the Royal Society of London: Series $B, 329,99-108$.

WhitTleseA, B. W. A. (1993). Illusions of familiarity. Journal of Experimental Psychology: Learning, Memory, \& Cognition, 19, 1235 1253.

Whittlesea, B. W. A., JacoBy, L. L., \& Girard, K. (1990). Illusions of immediate memory: Evidence of an attributional basis for feelings of familiarity and perceptual quality. Journal of Memory \& Language, 29, 716-732.

Yonelinas, A. P., Kroll, N. E. A., Dobbins, I., Lazzara, M., \& KNIGHT, R. T. (1998). Recollection and familiarity deficits in amnesia: Convergence of remember-know, process dissociation, and receiver operating characteristic data. Neuropsychology, 12, 323-339.

(Manuscript accepted for publication April 7, 1998.) 